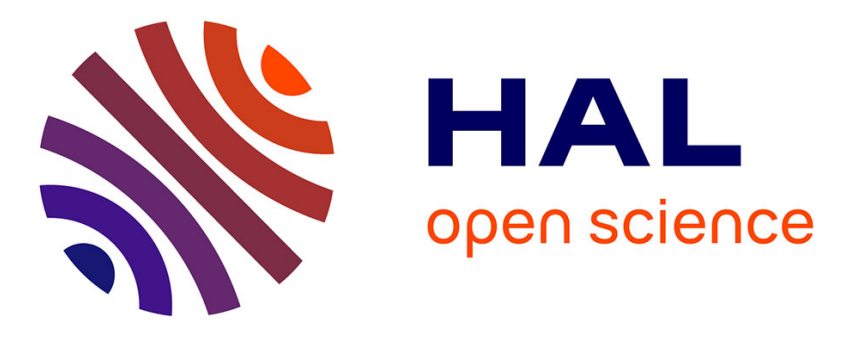

\title{
Bringing It All Back Home Return migration and fertility choices
}

Simone Bertoli, Francesca Marchetta

\section{To cite this version:}

Simone Bertoli, Francesca Marchetta. Bringing It All Back Home Return migration and fertility choices. 2012. halshs-00659292

\section{HAL Id: halshs-00659292 \\ https://shs.hal.science/halshs-00659292}

Preprint submitted on 12 Jan 2012

HAL is a multi-disciplinary open access archive for the deposit and dissemination of scientific research documents, whether they are published or not. The documents may come from teaching and research institutions in France or abroad, or from public or private research centers.
L'archive ouverte pluridisciplinaire HAL, est destinée au dépôt et à la diffusion de documents scientifiques de niveau recherche, publiés ou non, émanant des établissements d'enseignement et de recherche français ou étrangers, des laboratoires publics ou privés. 
CENTRE D'ETUDES

ET DE RECHERCHES

SUR LE DEVELOPPEMENT

INTERNATIONAL
Document de travail de la série

\section{Etudes et Documents}

E 2012.01

Bringing It All Back Home

Return migration and fertility choices

Simone BERTOLI

Francesca MARCHETTA 


\section{Les auteurs}

\section{Simone Bertoli}

Maitre de conférences, Clermont Université, Université d'Auvergne, CNRS, UMR 6587, Centre d'Etudes et de Recherches sur le Développement International (CERDI), F-63009 ClermontFerrand, France

Email : simone.bertoli@u-clermont1.fr

\section{Francesca Marchetta}

Post-doc, Clermont Université, Université d'Auvergne, CNRS, UMR 6587, Centre d'Etudes et de Recherches sur le Développement International (CERDI), F-63009 Clermont-Ferrand, France Email : francesca.marchetta@u-clermont1.fr

Corresponding author: simone.bertoli@u-clermont1.fr

La série des Etudes et Documents du CERDI est consultable sur le site :

\section{http://www.cerdi.org/ed}

Directeur de la publication : Patrick Plane

Directeur de la rédaction : Catherine Araujo Bonjean

Responsable d'édition : Annie Cohade

ISSN : 2114-7957

\section{Avertissement :}

Les commentaires et analyses développés n'engagent que leurs auteurs qui restent seuls responsables des erreurs et insuffisances. 


\section{Abstract}

Return migration exerts wide-ranging influence upon the countries of origin of the migrants. We analyze whether returnees adjust their fertility choices to match the norms which prevail in their previous countries of destinations, using Egyptian household-level data. Egyptians migrate predominantly towards other Arab countries characterized by higher fertility rates. Relying on a two-step instrumental variable approach to control for the endogeneity of the migration decisions, we show that return migration has a significant and positive influence on the total number of children. These results suggest that migration might not be an unmitigated blessing for Egypt, as it has contributed to slow down the process of demographic transition.

JEL Classification: F22; J13; O15.

Key Words: temporary migration; fertility; household-level data; Egypt.

\section{Acknowledgements}

The authors are grateful to Jean-Louis Combes for his comments on an earlier draft of this paper; the usual disclaimers apply. 


\section{Introduction}

"Des millions d'Égyptiens se sont précipités vers les pays du Golfe pour aller y travailler et ils en sont revenus, quelques années plus tard, avec de l'argent et des idées wahabites. [...] Or les wahabites ne voient en la femme qu'un réceptacle sexuel, un instrument de tentation, ou un moyen d'avoir des enfants. ${ }^{1}$ Alaa El Aswany (2011), Chroniques de la Révolution Égyptienne

The relevance of international migration goes well beyond the movement of people, as migration also represents a powerful mechanism to transmit ideas across borders. With respect to the flows of ideas towards the countries of origin, Spilimbergo (2009) shows student migration towards democratic countries promote democracy at home, while Batista and Vicente (2011) and Docquier, Lodigiani, Rapoport, and Schiff (2011) show that migration can improve the quality of domestic institutions. Return migrants can bring back home a stronger entrepreneurial attitude (Piracha and Vadean, 2010; Démurger and Xu, 2011), and the prospect to migrate reshapes the incentives to invest in education (Mountford, 1997; Stark, Helmenstein, and Prskawetz, 1997; Beine, Docquier, and Rapoport, 2001, 2008; Docquier and Rapoport, 2011).

International migration can also influence fertility decisions at origin, as it changes the incentives of the parents (Mountford and Rapoport, 2011) and it exposes them to the fertility norms which prevail at destination (Fargues, 2007, 2011; Beine, Docquier, and Schiff, 2008). ${ }^{2}$ Specifically, Fargues $(2007,2011)$ first suggested that fertility at origin can be endogenous to migration: sending countries whose migrants are directed towards destinations where women have a lower number of children should see a reduction in their levels of fertility, while the reverse occurs when migrants move towards countries which are characterized by a higher number of children per woman. Beine, Docquier, and Schiff (2008) provide evidence of this migration-induced transfer of fertility norms using aggregate data using the data on bilateral migrant stocks presented in Ozden, Parsons, Schiff, and Walmsley (2011). These results suggest that migration towards high-income OECD countries can contribute to

\footnotetext{
1 "Millions of Egyptians rushed towards the Gulf Countries to find a job there and they came back, after a few years, with some money and with wahhabi ideas. [...] Wahhabism regards women as a sexual object, an instrument of temptation, or a mean to have children." (our translation from French).

${ }^{2}$ International migration is not included among the determinants of demographic transition in the recent survey by Galor (2011).
} 
narrow down the demographic imbalances between the countries of origin and destination, ${ }^{3}$ while migration towards high-income and high-fertility countries, such as the Arab countries in the Gulf, can slow down the demographic transition at origin.

Migration towards the high-income Arab countries is almost exclusively male and predominantly temporary in nature, and hence one can reasonably expect that returnees would be the primary and direct channel of transmission of the fertility norms which prevail at destination. The objective of this paper is to understand whether the couples where the husband is a returnee from a high-fertility destination country have a larger number of children than couples of stayers. Specifically, we test whether a temporary migration experience in an Arab country exerts a significant influence on the fertility choices of Egyptian households. ${ }^{4}$ As recalled in the initial quote from Alaa El Aswany, Egypt has been experiencing massive waves of migration towards Arab oil-producing countries since the early 1970s, and we are going to use household-level data to analyze the relationship between the past migration experience and current fertility decisions.

We estimate a Poisson regression where the dependent variable is represented by the total number of live births recorded by a couple at the time of the 2006 Egyptian Labor Market Panel Survey which represents our main source of data. A key analytical challenge is represented by the non-random selection of Egyptian migrants with respect to unobservable characteristics which have an impact on their fertility decisions. Egyptian male migrants to Arab countries might be open-minded individuals with loose family ties, or they might have conservative attitudes which resonate well with the social and cultural values that prevail at destination. We tackle the threat to identification posed by the endogeneity of the decision to migrate following Wahba and Zenou (2009), who rely on the fluctuations in the real price of oil to obtain an exogenous source of variability in the probability to migrate. The use of this instrument opens up the question of the age at which each male individual in our sample has to be matched to the corresponding real price of oil, and we rely on an explicit optimality criterion to chose among the alternative options. As our equation of interest is

\footnotetext{
${ }^{3}$ See Hanson and McIntosh (2010b,a) for recent evidence on the role of demographic push factors in international migration, and Hatton and Williamson (1998) for an account of their role during the age of mass migration at the turn of the twentieth century.

${ }^{4}$ The literature has already analyzed the influence of return migration to Egypt upon wages (Wahba, 2007), upon the occupational choices (Wahba and Zenou, 2009), and upon the chances of survival of entrepreneurial activities Marchetta (2011).
} 
non linear, we implement our instrumental variable strategy using the two-stage residual inclusion, 2SRI, estimator proposed by Terza, Basu, and Rathouz (2008).

This two-step approach allows us to remove the bias due to the non-random selection into migration, but it does not allow us to isolate the transfer of fertility norms which influence preferences towards the desired number of children. What we estimate is the aggregate effect of the migration experience, which might also capture the loosening of subsistence constraints, a reduced demand for old-age security induced by the savings accumulated abroad, or changes in the opportunity costs of child rearing. ${ }^{5}$ Still, a large positive effect of migration experience on the number of children would be strongly suggestive of the role played by the transfer of fertility norms from the Arab countries of destination of Egyptian migrants. Furthermore, return migration could exert an influence which goes beyond its direct effect which we estimate: returnees could play a catalytic role, ${ }^{6}$ spreading changing attitudes towards fertility also towards stayers. If return migration also has a diffuse influence upon other Egyptians, then the comparison of returnees with stayers in the econometric analysis would provide us with a lower bound of the actual direct impact upon returnee households.

The estimates reveal that Egyptian couples where the husband is a returnee from an Arab countries have a significantly larger number of children. The result is actually stronger once we control for the endogeneity of the migration decisions through the adoption of the twostage residual inclusion estimator. The real oil price enters significantly and with a positive coefficient in the first stage equation, and the generalized residuals that we compute from this auxiliary regression have a negative and significant impact on the total number of children. This confirms that migration experience is endogenous, and it reveals that returnees have on average unobservable characteristics which are associated with a lower level of fertility.

The paper is structured as follows: Section 2 presents the econometric approach used to identify the impact of return migration on fertility decisions. Section 3 describes the sources of the data, and it presents relevant descriptive statistics. Section 4 presents the estimates and the robustness checks, and Section 5 discusses the main results of the econometric

\footnotetext{
${ }^{5}$ See Beine, Docquier, and Schiff (2008) and Mountford and Rapoport (2011) for an overview of the channels through which migration can influence fertility decisions at origin.

6 "[M] edia attention is also likely to focus on the situation of return migrants, including their economic performance, views and behavioral modes, and how they might differ from those of natives." (Beine, Docquier, and Schiff, 2008).
} 
analysis and draws the main conclusions.

\section{Empirical strategy}

Let $q_{i}$ denote the number of children of the woman $i$; if $q_{i}$ follows a univariate Poisson process, then:

$$
\operatorname{Pr}\left(q_{i}=y\right)=\frac{e^{-\mu_{i}} \mu_{i}^{y}}{y !}, \text { with } y \in \mathbb{N}_{0}
$$

where the parameter $\mu_{i}$ in (1) represents the mean and the variance of $q_{i}$, and which we assume to the an exponential function of a vector $\boldsymbol{x}_{i}$ of covariates, that is:

$$
\mu_{i}=e^{\boldsymbol{x}^{\prime} \boldsymbol{\beta}+u_{i}} .
$$

The error term $u_{i}$ in (2) follows:

$$
u_{i}=\rho \epsilon_{i}+\nu_{i} .
$$

The vector of covariates $\boldsymbol{x}_{i}=\left(y_{2 i}, \boldsymbol{x}_{1 i}{ }^{\prime}\right)^{\prime}$ in (2) includes a sub-vector $\boldsymbol{x}_{1 i}$ whose elements are uncorrelated with (3), and one regressor $y_{2 i}$ which is orthogonal to $\nu_{i}$ but correlated with $\epsilon_{i}$. The estimation of the determinants of the number of children $q_{i}$ will deliver a consistent estimate of the vector of coefficients $\boldsymbol{\beta}$ only if $\rho=0$, as this condition entails the exogeneity of $y_{2 i}$, while $y_{2 i}$ will be endogenous whenever $\rho \neq 0$.

In our case, $y_{2 i}$ is a dichotomous variable which is equal to one if the husband of woman $i$ is a returnee from an Arab country. If Egyptian migrants are not randomly selected in unobservables that also influence the fertility choices of the couple, then we need to tackle the threat to identification posed by the endogeneity of migration in the fertility equation. Let:

$$
\operatorname{Pr}\left(y_{2 i}=1 \mid \boldsymbol{x}_{1 i}, \boldsymbol{x}_{2 i}\right)=\Phi\left(\boldsymbol{x}_{1 i}{ }^{\prime} \boldsymbol{\gamma}_{\mathbf{1}}+\boldsymbol{x}_{2 i}{ }^{\prime} \boldsymbol{\gamma}_{\mathbf{2}}\right),
$$

where the vector $\boldsymbol{x}_{2 i}$ is excluded from (2), and $\Phi($.$) represents the cumulative density$ function of the standard normal distribution. The generalized residual (Gourieroux, Monfort, Renault, and Trognon, 1987) from (4) is represented by: 


$$
\widetilde{e}_{i}(\widehat{\gamma})= \begin{cases}\phi\left(\boldsymbol{x}_{1 i}{ }^{\prime} \widehat{\gamma}_{1}+\boldsymbol{x}_{2 i}{ }^{\prime} \widehat{\gamma}_{2}\right) / \Phi\left(\boldsymbol{x}_{1 i}{ }^{\prime} \widehat{\gamma}_{1}+\boldsymbol{x}_{2 i}{ }^{\prime} \widehat{\gamma}_{2}\right) & \text { if } y_{2 i}=1 \\ \phi\left(\boldsymbol{x}_{1 i}{ }^{\prime} \widehat{\gamma}_{1}+\boldsymbol{x}_{2 i}{ }^{\prime} \widehat{\gamma}_{2}\right) /\left[1-\Phi\left(\boldsymbol{x}_{1 i}{ }^{\prime} \widehat{\gamma}_{1}+\boldsymbol{x}_{2 i}{ }^{\prime} \widehat{\gamma}_{2}\right)\right] & \text { if } y_{2 i}=0\end{cases}
$$

where $\phi($.$) represents the probability density function of the standard normal distribution,$ and $\widehat{\gamma}=\left(\widehat{\gamma}_{1}^{\prime}, \widehat{\gamma}_{2}^{\prime}\right)^{\prime}$. Terza, Basu, and Rathouz (2008) demonstrate that a consistent estimate of the vector of coefficients $\boldsymbol{\beta}$ can be obtained by replacing the unobserved component of the error $\epsilon_{i}$ with the generalized residual $\widetilde{e}_{i}(\widehat{\gamma})$, while keeping the observed value of the endogenous covariate $y_{2 i}$ in the vector of regressors. The reliance on this two-stage residual inclusion, 2SRI, estimator has been also proposed by Cameron and Trivedi (2010) in the specific case where the equation of interest is Poisson, and it has been applied by Fang, Eggleston, Rizzo, and Zeckhauser (2010) for the analysis of the determinants of fertility in rural China. The non-linearity of the second stage equation implies the inconsistency of the estimates of $\boldsymbol{\beta}_{1}$ and $\beta_{2}$ obtained with with the two-stage predictor substitution estimator, which would require to estimate (4), and then replace the endogenous regressor $y_{2 i}$ with its predicted value $\hat{y}_{2 i}$ (Terza, Basu, and Rathouz, 2008).

The Poisson equation to be estimated through maximum likelihood thus becomes:

$$
\mu_{i}=e^{\boldsymbol{x}_{1 i}{ }^{\prime} \boldsymbol{\beta}_{1}+\beta_{2} y_{2 i}+\rho \widetilde{e}_{i}(\widehat{\gamma})+\nu_{i}} .
$$

The estimate of $\boldsymbol{\beta}$ obtained through maximum likelihood retain their consistency even if the data are not Poisson-distributed, provided that the conditional mean $\mu_{i}$ in (6) is correctly specified (Gourieroux, Monfort, and Trognon, 1984). The relaxation of the distributional assumptions on the error term requires to estimate the standard errors in a way that is robust to the violation of the equidispersion property of the Poisson distribution. Whenever the estimated coefficient $\hat{\rho}$ is significantly different from zero, one has to resort to bootstrapping to account for the additional variability which is introduced in (6) by the estimation of the generalized residuals $\widetilde{e}_{i}(\widehat{\gamma})$.

\section{The data}

Our data come from the 2006 wave of the Egyptian Labour Market Panel Survey, ELMPS, undertaken by the Central Agency for Public Mobilization and Statistics, CAPMAS, and by the Economic Research Forum, ERF. This nationally representative survey provides indirect 
information on the international migration experiences of the household members, including those who were absent at the time of the survey, and it also contains a complete record of the offspring of married women aged 16 to 49. The ELMPS 2006 allows us to identify as returnees the individuals who report to have been residing or working abroad before the survey. Specifically, the survey contains questions about the last two places of residence before the one at the time of the survey, and about the locations of the previous two jobs held by the respondents, while it does not contain any specific question on past migration experiences. This entails that we can identify as a returnee all individuals who report a foreign country in the answer to any of these four questions. Such an identification of the returnees is possibly subject to some measurement error, as we classify as a stayer a returnee who changed residence and job more than twice after his return to Egypt. The ELMPS 2006 also provides data on the year in which a respondents started their previous two jobs; for returnees, this variable can provide us with an upper bound of the age at the time of migration. ${ }^{7}$

Our sample includes married couples where the women are aged 16 to 49, and we exclude those women whose spouses $(i)$ are currently abroad, or $(i i)$ migrated to a non-Arab country in the past. 8

These two sample selection criteria allow us to focus on Egyptian returnees from Arab countries only, The ELMPS 2006 includes only 25 returnees from non-Arab countries; this low figure is consistent with the predominantly permanent character of Egyptian migration towards these countries. and to compare them with the sample of never-migrant households. The resulting sample includes 5,732 married couples, with 394 of them, corresponding to 7.5 percent of the population of reference, including a husband who has migrated to an Arab country in the past (see Table 3).

The Arab countries of destination of Egyptian returnees that are recorded in the ELMPS 2006 are Algeria, Iraq, Jordan, Kuwait, Lebanon, Libya, Oman, Qatar, Saudi Arabia, Syria, United Arab Emirates and Yemen, with Saudi Arabia representing the most relevant migrant

\footnotetext{
${ }^{7}$ The actual age at migration is lower than the one provided by this proxy if the returnee frequently changed his job, so that the survey fails to record the first job positions held abroad.

${ }^{8}$ The data on real oil prices, which are available from 1947, induce us to drop out of the sample the couples where the husband was older than 69 years at the time of the survey. As we associate to each husband the real price of oil at the age of 20 (see Section 4 on this), we also excluded from the sample the couples with a husband aged below 20 years in 2006 .
} 
destination, as evidenced in Table $1 .^{9}$ According to the matrix of bilateral migrant stocks presented in Ozden, Parsons, Schiff, and Walmsley (2011), the 12 countries of destination included in Table 1 hosted 79.0 percent of the Egyptians residing abroad in 2000, ${ }^{10}$ though this figure probably understates the relevance of these destinations given the predominant temporary character of Egyptian migration towards these countries.

Table 3 presents some key descriptive statistics. The couples where the husband is a returnee from an Arab country have on average 3.24 children, while stayers have on average 2.57 children. The difference is substantial, and it probably reflect some relevant differences between the two groups with respect to observable characteristics: the duration of the wedding for returnees stands at 15.64 years, above the corresponding figure for stayers which stands at 11.87. For both groups, husbands are significantly older then their wives: male stayers are nearly seven years older than their spouses, while the age differential in returnee couples exceeds eight years. Wives in both groups have around 6.7 years of completed schooling, while male returnees have 6.8 years of completed schooling, below the 7.3 years recorded for stayers. Table 3 also reports the level of education and the number of children of the mothers of the wives included in our sample, which are consistent both the improvement in the level of education and the decline in fertility levels in Egypt over the past few decades. While, as recalled above, the married women aged 16 to 49 who form our sample have on average 6.67 years of completed schooling, 79 percent of their mother were illiterate. They had, on average 6.49 children, well above the 2.63 recorded for their daughters, though this difference is also affected by the fact that most the women in the latter group were still fertile at the time of the survey.

Table 3 also reveals that when returnees were 20 years old, they faced a real oil price equal to USD 49.84, while the corresponding figure for stayers stands at USD 39.41. This is consistent with the idea that the decision to migrate towards an Arab country is influenced by labor market conditions at destination, which are in turn deeply shaped by the ups and downs in the evolution of the price of oil.

Figure 1 plots the evolution of the share of male returnees by year of birth between 1950

\footnotetext{
${ }^{9}$ Observe that each returnee could have had more than one migration episode, possibly in different destination countries.

${ }^{10}$ The corresponding figure for 1990 stands at 80.3 percent, up from 71.4 percent in 1980 and 51.8 percent in 1970 .
} 
and 1986, together with the real price of oil between measured at the age of 20 years. ${ }^{11}$ Figure 1 shows that the share of returnees is highest, close to 20 percent, for the Egyptians born at the end of the 1950s, who probably migrated to other Arab countries at in correspondence with the second oil crisis at the end of the 1970s and early 1980s. After this peak, the share of returnees fell, together with the steady decline of the real price of oil up to the end of the 1990s. The comparison of the two series for the males born after 1980 signals a surge in the real price of oil, with no corresponding increase in the share of returnees, as most recent Egyptian migrants had not yet completed their migration experience at the time of the survey.

\section{Econometric analysis}

The vector of regressors $\boldsymbol{x}_{1 i}$ which is expected to influence the number of children $q_{i}$ of woman $i$ in our sample includes $(i)$ the duration of the wedding, (ii) characteristics of the wife, (iii) characteristics of her mother and (iv) characteristics of the husband. Specifically, with respect to $(i i)$ we include the age of at the time of the wedding, while for (iii) we control for the level of education of the mother and for the number of children that she had. ${ }^{12}$ With respect to the husband, beyond the migration experience, we control for the completed number of years of schooling. Furthermore, we also control for the distance to the nearest health clinic, and we include regional dummies, which remove from the estimates the influence of spatial differences in the incidence of migration which correlate with preferences towards the number of children. We opted for a parsimonious specification of $\boldsymbol{x}_{1 i}$ to reduce the concerns, though possibly not to eliminate them completely, connected to the possible endogeneity of its elements. ${ }^{13}$ We provide evidence below that this selection of regressors suffices to reach a good fit of the observed fertility choices in our sample, measured, as suggested by Cameron and Trivedi (2010), by the correlation between the actual and the predicted values of the dependent variable.

\footnotetext{
${ }^{11}$ Figure 1 is built upon 5,472 out of 5,732 Egyptian males in our sample.

${ }^{12}$ Booth and Kee (2009) provide evidence of the intergenerational transmission of fertility patterns.

${ }^{13}$ Regrettably, the ELMPS 2006 does not provide sufficient retrospective information to control for the economic condition of the household or the labor market participation of the wife, nor it provides information on the employment status of their parents.
} 


\subsection{Selection of the instrument}

Beyond the controls included in the vector $\boldsymbol{x}_{1 i}$, the key variable of interest is represented by $y_{2 i}$, which describes the past migration experience of the husband in an Arab country.

Following Wahba and Zenou (2009), we rely on the real price of oil to obtain an exogenous dimension of variability in $y_{2 i} \cdot{ }^{14}$ This variable can have a substantial influence on the scale of migration towards oil-producing countries which adopt employer-driven immigration systems which respond to fluctuations in local economic conditions. ${ }^{15}$ Furthermore, as Egyptian migration towards Arab countries is almost exclusively temporary in nature, a variable which predicts the beginning of the migration experience is also a suitable instrument for return migration.

The use of the real price of oil as an instrument for migration experience requires to select the age at which each male individual in the sample has to be associated to the corresponding real oil price. ${ }^{16}$ We adopted the following criterion to guide our choice: we estimated the auxiliary regression which is used to generate the generalized residuals $\widetilde{e}_{i}(\widehat{\gamma})$ using as an instrument $x_{2 i s}$, which is the real price of oil measured when the individual $i$ in our sample was $s$ years old, for $s=18, \ldots, 28 \cdot{ }^{17}$ Then, for each specification, we tested the null hypothesis that the estimated coefficient of $x_{2 i s}$ is equal to zero through a $\chi^{2}(1)$ test, and we selected the age $s$ which produced the highest value of the test statistics. Figure 2 reports the test statistics for each of the specification of the auxiliary regression, together with the 1 percent critical value of the $\chi^{2}$ distribution with one degree of freedom.

The value of the test statistics is highest when $s$ is equal to 20, and it falls below the 1 percent critical value for $s \geq 26$. Hence, we selected as our instrument $x_{2 i}$ the real oil

\footnotetext{
${ }^{14}$ Binzel and Assaad (2011) rely on the size of village-level migration networks, derived from the 2006 Population Census, to instrument for current migration episodes; measures of the past size of networks would not represent a valid instrument for our analysis if the size of networks correlates with persistent differences in fertility norms across different geographical areas.

${ }^{15}$ Arab countries have extensively relied on the kafala, or sponsorship, system to regulate the inflow of temporary immigrants, which could obtain an entry visa only through a local sponsor (Gardner, 2011).

${ }^{16}$ As described in Section 3, the ELMPS 2006 does not provide accurate information on the age at migration; the proxy represented by the year in which a returned took up a job position abroad, which is non-missing for 334 out of the 394 returnees in our sample, reveals that the median and modal ages at migration are 24 and 22 years respectively.

${ }^{17}$ The estimates were conducted on the subsample for which $x_{2 i s}$ is non-missing for all $s=18, \ldots, 28$. The choice of the instrument is unaffected if we let the sample vary across specifications.
} 
price measured when the husband was 20 years old. ${ }^{18}$ Wahba and Zenou (2009) opt for the real price of oil at the age of 28 years, with Figure 2 revealing that this would be a highly suboptimal choice on our sample and given the specification of the auxiliary regression. The choice of our instrument entails that we restrict our sample to the couples for which we have information on the real price of oil in the year in which the husband was 20 years old.

\subsection{Estimation results}

Table 4 presents the benchmark estimates of our fertility regression, which retain their consistency even if the error term is not Poisson-distributed. ${ }^{19}$ Specification (1), which does not include the migration experience of the husband among the regressors, shows that the duration of the wedding exerts, as expected, a positive and highly statistically significant impact on the number of children of the couple. The coefficient of the age of the wife at the time of the wedding is negative, albeit only marginally significant in this specification, revealing that an early wedding is associated, even controlling for its duration, with a higher number of children. Fertility is declining with the level of education of the mother of the wife, while it is significantly increasing with the number of children of the previous generation. Fertility falls with the completed years of schooling of the husband. ${ }^{20}$ Specification (1) also reveals that the total number of children is increasing with the time which is required to reach the nearest health clinic, and for households who reside in rural areas. The inclusion of regional dummies allows us to have a correlation of 0.56 between the actual and the predicted number of children for the couples in our sample.

Specification (2) in Table 4 introduces the migration experience of the husband among the regressors. The estimated coefficient is positive and highly statistical significant. Still, the threat to identification posed by the possible correlation of this variable with the error

\footnotetext{
${ }^{18}$ We would have chosen the same instrument if we adopted as the guiding criterion the age $s$ at which the simple bivariate correlation between $x_{2 i}$ and the migration variable $y_{2 i}$ attains its highest value; the use of more than one oil price is precluded by the associated multicollinearity problem.

${ }^{19}$ Regression-based tests following Cameron and Trivedi (1990) on the null hypothesis that the data are equidispersed lead to a rejection of the null; the standard errors presented in all specifications are robust to the violation of the mean-variance equality which characterizes a Poisson distribution.

${ }^{20}$ The estimation results, which are available upon request from the authors, are not sensitive to the inclusion of the level of schooling of the wife, which is strongly and positively correlated with the one of the husband.
} 
term entails that we should not blur correlation with causation.

As discussed in Section 2, we tackle the endogeneity of this regressor through the adoption of the 2SRI estimator: we first estimate the auxiliary probit regression described in (4), where the estimated coefficient $\widehat{\gamma}_{2}$ of the real price of oil at the age of 20 is positive and significant, ${ }^{21}$ and then we compute the generalized residuals $\widetilde{e}_{i}(\widehat{\gamma})$. Specification $(3)$ in Table 4 includes the generalized residuals among the regressors: the estimated coefficient is significant, confirming that the migration experience variable is endogenous, and negative, suggesting that Egyptian migrants to Arab countries are self-selected among the individuals with unobservable characteristics which are associated with a lower level of fertility. The inclusion of the generalized residuals also induces a marked increased in the point estimate of the coefficient of the endogenous migration experience variable, though the analytic standard errors reported in specification (3) cannot be relied upon to assess its significance, as they neglect the variability associated with the estimated auxiliary regressor $\widetilde{e}_{i}(\widehat{\gamma})$.

Specification (4) provides the estimates of the specification which includes the generalized residuals, reporting the standard errors obtained with bootstrapping. The bootstrapped standard error associated to the estimated coefficient for return migration is larger than the analytic standard error, but it still allows us to reject at the 1 percent confidence level the null hypothesis that the coefficient is equal to zero. The estimated coefficients for the other regressors are largely unaffected by the adoption of the 2SRI estimator.

As in any non-linear model, the effect of a change in any of the regressors, depends on the values of all other covariates. Using (6), the estimated effect of return migration upon the total number of children of a couple, once we account for its endogeneity, is given by:

$$
\begin{array}{r}
E\left[\mu_{i} \mid y_{2 i}=1, \hat{\boldsymbol{\beta}}, \hat{\rho}, \boldsymbol{x}_{1 i}, \widetilde{e}_{i}(\widehat{\gamma})\right]-E\left[\mu_{i} \mid y_{2 i}=0, \hat{\boldsymbol{\beta}}, \hat{\rho}, \boldsymbol{x}_{1 i}, \widetilde{e}_{i}(\widehat{\gamma})\right]= \\
\left(e^{\hat{\beta}_{1}}-1\right) e^{\boldsymbol{x}_{1 i}{ }^{\prime} \hat{\boldsymbol{\beta}}_{1}+\hat{\rho} \widetilde{e}_{i}(\widehat{\gamma})},
\end{array}
$$

where $\hat{\boldsymbol{\beta}}=\left(\hat{\boldsymbol{\beta}}_{1}^{\prime}, \hat{\beta}_{2}\right)^{\prime}$. Computing (7) for the sub-sample of returnees gives us the average treatment effect on the treated: return migration from an Arab country increases the predicted total number of children by 1.37 children, with a standard error of 0.32 associated to this point estimate. This figure is above the difference in the observed number of children between returnees and stayers, which stands at 0.67 children as evidenced in Table 3 , and

\footnotetext{
${ }^{21}$ The estimated coefficient of the real price of oil in this specification stands at 0.007 , with a standard error of 0.001 ,
} 
above the difference 0.21 that can be estimated according to (7) on the basis of specification (2) in Table 4, which controls for the differences in observables only between the two groups. This is consistent with the estimated negative and significant coefficient for the generalized residuals $\widetilde{e}_{i}(\widehat{\gamma})$ : the married couples where the husband is a returnee from an Arab country are endowed with unobservable characteristics which are negatively associated with their total number of children. Before moving to the discussion and possible interpretation of this result, we subject it to a number of robustness checks which are described below.

\subsection{Robustness checks}

Figure 1 evidenced that the sharp increase in the real price of oil since the end of the 1990s is not matched by a corresponding increase in the share of returnees. This does not reflect a structural change in the relationship that we relied upon to derive an exogenous source of variability in migration, but rather to the Egyptians who moved to an Arab country in response to this increase in the real price of oil had not yet come back home at the time of the survey. ${ }^{22}$ Specifications (1)-(2) in Table 5 report the estimates obtained when we restrict the sample to the couples where the husband was at least 25 years old at the time of the survey. The results are virtually unaffected by this restriction.

Our identification strategy is centered around the role of the real price of oil in influencing the size of Egyptian migration. Still, some of the 12 destination countries in our sample, such as Jordan which is the third most relevant destination according to Table 1, are actually not oil producers. Specifications (3)-(4) in Table 5 restrict the estimation to the sample which includes only stayers and returnees from a country which is member of the OPEC. The estimates obtained both when treating migration status as exogenous and when accounting for its endogeneity with the proposed two-step estimation are unchanged by a restriction of the sample which is fully consistent with our identification strategy.

While the real price of oil represents a relevant pull factor driving Egyptian migrants towards other Arab countries, it can also be correlated with economic conditions at origin, which might influence the fertility choices of stayers. For instance, the 1967 Kippur War led both to a surge in the real price of oil, and to the closure for eight years of the Suez Canal, which imposed a heavy toll on the Egyptian economy. Beyond this specific historical case, the fluctuations in the real price of oil can have an impact on economic conditions in

\footnotetext{
${ }^{22}$ Nassar (2008) documents an increase in the number of Egyptian migrants since 1999.
} 
Egypt via the real exchange rate. We address the concern related to the possible violation of the exclusion restriction showing that our findings are robust to the inclusion of controls for business cycle conditions in Egypt. Specification (5) in Table 5 includes the rate of growth of real GDP per capita when the husband was 20 years old among the controls, to capture the influence of the price of oil on the fertility choices of stayers which might go through its impact on economic conditions in Egypt. The estimated coefficient of this additional regressor is negative but not significantly different from zero, while the estimated effect of the migration experience is positive and significant at the 5 percent confidence level.

Although Table 2 did not evidence major differences in the level of fertility across the Gulf countries and the other Arab countries of destination of the Egyptian migrants, the initial quote of this paper from Alaa El Aswany makes an explicit reference to the effects of temporary migration towards the Gulf countries, as these are characterized by an extremely conservative perception of the role of women in the society. Specifications (1)-(2) in Table 6 restrict the sample to stayers and returnees from a Gulf country. ${ }^{23}$ The results are in line with our baseline result, and the estimated coefficient of migration experience is positive and significant at the 5 percent confidence level once standard errors are obtained through bootstrapping.

Table 2 showed that the total number of children per woman in Egypt was lower than in all the destination countries but Lebanon in the early 1970s. Over time, fertility in several Arab countries declined at a faster pace than in Egypt, so that six destination countries had a lower number of children than Egypt by the early 2000s. The hypothesis set out by Fargues $(2007,2011)$ implies that returnees from destination countries with a higher fertility should, ceteris paribus, increase their number of children. In line with this argument, Table 6 drops out of the sample the Egyptian returnees from countries which had, at different points in time from 1980 to 1995, a lower level of fertility than Egypt. For instance, Specification (6) excludes returnees from Algeria Kuwait, Lebanon, Libya and Qatar, as these countries had a total number of children per woman which fell short of the corresponding Egyptian figure in 1995. Table 6 reports the estimates obtained with the 2SRI estimator on four different samples: the generalized residuals are still negative and significant at the 5 percent confidence level, and our key variable of interest is still positive and significant at the 1 percent confidence in all specifications but (2) and (6), where the null is rejected at the 5

\footnotetext{
${ }^{23}$ Hence, we exclude returnees from Algeria, Jordan, Lebanon, Lybia, and Syria.
} 
percent confidence level.

We also tested the robustness of our results to the selection of a different age at which each male individual in the sample is matched with the real price of oil. Our results, which are not reported but are available from the authors upon request, proved to be robust to the choice of either the age of 18 or 19 which, as evidenced in Figure 2, displayed the highest value of the $\chi^{2}(1)$ test statistics after our preferred instrument. Estimates obtained when selecting the real price of oil at the age of 21 or above as the instrument in the auxiliary regression turned out to be not significant, in line with the sharp fall in the respective $\chi^{2}(1)$ test statistics.

\section{Concluding remarks}

The analysis presented in this paper showed that the Egyptian married couples where the husband has a past migration experience in another Arab country have a significantly larger number of children than stayers. The estimates, which have proved to be robust to a number of robustness checks, are stronger once we control for the endogeneity of self-selection into migration with the two-stage residual inclusion estimator. The direction of the bias induced by the endogeneity of the migration experience in the Poisson regression suggests that Egyptian migrants are on average endowed with unobservable characteristics which would have induced them to have a lower number of children, had they not migrated. The point estimates of the impact of return migration upon the total number of children in returnee households range between 1.14 and 1.43 children in the various specifications presented in Tables 4-6. A back-of-the-envelope calculation of the average fertility rate in the countries of destination of Egyptian migrants, made combining the data reported in Tables 1 and 2 reveals that this was between 1.04 and 1.55 children per woman higher than in Egypt from 1970 to 2000. This suggests that Egyptian returnees have a number of children which is closer to the norm that prevails at destination than to the one prevailing at origin, in line with the hypothesis originally advanced by Fargues (2007, 2011).

These results are suggestive of the fact that Egyptian returnees "bring it all back home": they bring back the financial resources that allow them to opt for an entrepreneurial activity (McCormick and Wahba, 2001; Wahba and Zenou, 2009) and to keep it alive over time (Marchetta, 2011), but they also bring back conservative views on the role of women, which 
limit their participation on the labor market (Binzel and Assaad, 2011) and increase the number of children that they have. This suggests that the current pattern of temporary international migration might not be an unmitigated economic and social blessing for Egypt. 


\section{References}

Batista, C., And P. C. Vicente (2011): "Do Migrants Improve Governance at Home? Evidence from a Voting Experiment," World Bank Economic Review, 25(1), 77-104.

Beine, M., F. Docquier, and H. Rapoport (2001): "Brain drain and economic growth: theory and evidence," Journal of Development Economics, 64, 275-289.

Beine, M., F. Docquier, and H. Rapoport (2008): "Brain Drain and Human Capital Formation in Developing Countries: Winners and Losers," Economic Journal, 118(528), 631-652.

Beine, M., F. Docquier, And M. Schiff (2008): "International Migration, Transfers of Norms and Home Country Fertility," IZA Discussion Paper 3912, Institute for the Study of Labor, Bonn.

Binzel, C., And R. AssaAd (2011): "Egyptian men working abroad: Labour supply responses by the women left behind," Labour Economics, forthcoming.

Booth, A., And H. KeE (2009): "Intergenerational transmission of fertility patterns," Oxford Bulletin of Economics and Statistics, 71(2), 183-208.

Cameron, A., and P. Trivedi (2010): Microeconometrics Using Stata. College Station: Stata Press, revised edition.

Cameron, A. C., and P. K. Trivedi (1990): "Regression-based tests for overdispersion in the Poisson model," Journal of Econometrics, 46(3), 347-364.

DÉmurger, S., And H. Xu (2011): "Return Migrants: The Rise of New Entrepreneurs in Rural China," World Development, 39(10), 1847-1861.

Docquier, F., E. Lodigiani, H. Rapoport, and M. Schiff (2011): "Emigration and democracy," CReAM Discussion Paper Series No. 02/11, University College London.

Docquier, F., ANd H. Rapoport (2011): "Globalization, brain drain and development," Journal of Economic Literature, forthcoming. 
Fang, H., K. N. Eggleston, J. A. Rizzo, and R. J. Zeckhauser (2010): "Female Employment and Fertility in Rural China," Working Paper 15886, National Bureau of Economic Research.

FArgues, P. (2007): "The Demographic Benefit of International Migration: Hypothesis and Application to Middle Eastern and North African Contexts," in International Migration, Economic Development and Policy, ed. by C. Özden, and M. Schiff, pp. 161-182. Washington: The World Bank.

FArgues, P. (2011): "International Migration and the Demographic Transition: A TwoWay Interaction," International Migration Review, 45(3), 588-614.

Galor, O. (2011): "The Demographic Transition: Causes and Consequences," Working Paper 17057, National Bureau of Economic Research.

Gardner, A. M. (2011): "Gulf Migration and the Family," Journal of Arabian Studies, $1(1), 3-25$.

Gourieroux, C., A. Monfort, E. Renault, and A. Trognon (1987): "Generalized Residuals," Journal of Econometrics, 34, 5-32.

Gourieroux, C., A. Monfort, and A. Trognon (1984): "Pseudo Maximum Likelihood Methods: Applications to Poisson Models," Econometrica, 52(3), 701-720.

Hanson, G., And C. McIntosh (2010a): "Birth Rates and Border Crossings: Latin American Migration to the US, Canada, Spain, and the UK," Working Paper 16471, National Bureau of Economic Research.

Hanson, G. H., And C. McIntosh (2010b): "The Great Mexican Emigration," The Review of Economics and Statistics, 92(4), 798-810.

Hatton, T. J., and J. Williamson (1998): The Age of Mass Migration: Causes and Economic Impact. New York: Oxford University Press.

Marchetta, F. (2011): "Migration and the Survival of Entrepreneurial Activities in Egypt," RSCAS Working Paper 2011/01, European University Institute, Florence. 
McCormick, B., And J. WAhBa (2001): "Overseas work experience, savings and entrepreneurship amongst returnees to LDCs," Scottish Journal of Political Economy, 48, $164-178$.

Mountford, A. (1997): "Can a brain drain be good for growth in the source economy?," Journal of Development Economics, 53(2), 287-303.

Mountford, A., And H. Rapoport (2011): "The brain drain and the world distribution of income," Journal of Development Economics, 95(1), 4-17.

NAssaR, H. (2008): "Temporary and Circular Migration: the Egyptian Case," CARIM Analytic and Synthetic Notes No. 2008/09, Robert Schuman Centre for Advanced Studies, European University Institute.

Ozden, A., C. R. Parsons, M. Schiff, and T. L. Walmsley (2011): "Where on Earth is Everybody? The Evolution of Global Bilateral Migration 1960-2000," The World Bank Economic Review, 25(1), 12-56.

Piracha, M., And F. Vadean (2010): "Return Migration and Occupational Choice: Evidence from Albania," World Development, 38(8), 1141-1155.

Spilimbergo, A. (2009): "Democracy and Foreign Education," American Economic Review, 99(1), 528-43.

Stark, O., C. Helmenstein, and A. Prskawetz (1997): "A brain gain with a brain drain," Economics Letters, 86, 227-234.

Terza, J., A. Basu, and P. Rathouz (2008): "A two stage residual inclusion estimation: addressing endogeneity in health econometric modeling," Journal of Health Economics, 27, $531-543$.

WahbA, J. (2007): "Returns to Overseas Work Experience: The Case of Egypt," in International Migration, Economic Development and Policy, ed. by C. Özden, and M. Schiff, pp. 235-258. Washington: The World Bank.

Wahba, J., and Y. Zenou (2009): "Out of Sight, Out of Mind: Migration, Entrepreneurship and Social Capital," CReAM Discussion Paper Series No. 30/09 (Sept. 2011 revision), University College London. 
World BANK (2011): World Development Indicators. Washington: The World Bank. 
Table 1: Distribution of migration episodes across destination countries

\begin{tabular}{lcc} 
Country & Migration episodes & Share \\
\hline Saudi Arabia & 144 & 33.5 \\
Iraq & 137 & 31.9 \\
Jordan & 55 & 12.8 \\
Libya & 46 & 10.7 \\
Kuwait & 20 & 4.7 \\
United Arab Emirates & 11 & 2.6 \\
Lebanon & 5 & 1.2 \\
Qatar & 4 & 0.9 \\
Yemen & 4 & 0.9 \\
Oman & 2 & 0.5 \\
Algeria & 1 & 0.2 \\
Syria & 1 & 0.2 \\
Total & 430 & 100.0 \\
\hline
\end{tabular}

Figures based on the distribution of the migration episodes of the 394 male returnees in the sample; sampling weights not used.

Source: Authors' elaboration on ELMPS 2006 
Table 2: Total fertility rates in Egypt and in the Arab countries of destination, 1970-2004

\begin{tabular}{lccccccc} 
Country & $70-74$ & $75-79$ & $80-84$ & $85-89$ & $90-94$ & $95-99$ & $00-04$ \\
\hline Egypt & 5.77 & 5.50 & 5.25 & 4.81 & 4.04 & 3.52 & 3.21 \\
& & & & & & & \\
Algeria & 7.39 & 7.20 & 6.56 & 5.44 & 4.21 & 3.05 & 2.56 \\
Iraq & 7.23 & 6.83 & 6.42 & 6.15 & 5.84 & 5.45 & 5.18 \\
Jordan & 7.81 & 7.44 & 7.09 & 6.47 & 5.33 & 4.38 & 3.79 \\
Kuwait & 6.95 & 6.06 & 5.10 & 3.53 & 2.42 & 2.67 & 2.47 \\
Lebanon & 4.85 & 4.36 & 3.92 & 3.39 & 3.03 & 2.70 & 2.23 \\
Libya & 7.57 & 7.46 & 7.14 & 5.84 & 4.27 & 3.33 & 3.02 \\
Oman & 7.44 & 8.00 & 8.33 & 7.89 & 6.46 & 4.64 & 3.30 \\
Qatar & 6.78 & 6.21 & 5.49 & 4.64 & 4.01 & 3.41 & 3.03 \\
Saudi Arabia & 7.30 & 7.29 & 7.03 & 6.33 & 5.52 & 4.59 & 3.74 \\
Syria & 7.55 & 7.35 & 6.83 & 5.96 & 4.92 & 4.03 & 3.50 \\
United Arab Emirates & 6.39 & 5.75 & 5.28 & 4.84 & 3.99 & 3.07 & 2.47 \\
Yemen & 7.70 & 8.47 & 9.15 & 9.01 & 8.29 & 7.14 & 6.26 \\
\hline
\end{tabular}

Source: Authors' elaboration on World Bank (2011) 
Table 3: Descriptive statistics

\begin{tabular}{|c|c|c|c|c|}
\hline & & All sample & Stayers & Returnees \\
\hline \multirow[t]{8}{*}{ Couple } & Children & 2.63 & 2.57 & 3.24 \\
\hline & & $(1.94)$ & $(1.94)$ & $(1.88)$ \\
\hline & Duration of the wedding & 12.16 & 11.87 & 15.64 \\
\hline & & $(9.00)$ & $(9.02)$ & $(7.96)$ \\
\hline & Resident in rural areas & 0.58 & 0.57 & 0.66 \\
\hline & & $(0.49)$ & $(0.49)$ & $(0.47)$ \\
\hline & Distance from health clinic (minutes) & 14.30 & 14.35 & 13.61 \\
\hline & & $(10.02)$ & $(10.21)$ & $(7.32)$ \\
\hline \multirow[t]{14}{*}{ Wife } & Age & 31.83 & 31.51 & 35.86 \\
\hline & & $(8.62)$ & $(8.60)$ & $(7.79)$ \\
\hline & Age at the wedding & 19.68 & 19.63 & 20.22 \\
\hline & & $(4.17)$ & $(4.15)$ & $(4.34)$ \\
\hline & Years of schooling & 6.67 & 6.67 & 6.71 \\
\hline & & $(6.29)$ & $(6.30)$ & $(6.21)$ \\
\hline & Mother, number of children & 6.49 & 6.45 & 6.94 \\
\hline & & $(2.61)$ & $(2.58)$ & $(2.88)$ \\
\hline & Mother, illiterate & 0.79 & 0.79 & 0.78 \\
\hline & & $(0.40)$ & $(0.40)$ & $(0.42)$ \\
\hline & Mother, primary education & 0.18 & 0.18 & 0.20 \\
\hline & & $(0.38)$ & $(0.38)$ & $(0.40)$ \\
\hline & Mother, secondary and above & 0.03 & 0.03 & 0.02 \\
\hline & & $(0.17)$ & $(0.18)$ & $(0.14)$ \\
\hline \multirow[t]{10}{*}{ Husband } & Age & 38.69 & 38.26 & 43.94 \\
\hline & & $(9.96)$ & $(10.00)$ & $(7.77)$ \\
\hline & Age at the wedding & 26.53 & 26.39 & 28.30 \\
\hline & & $(5.79)$ & $(5.77)$ & $(5.78)$ \\
\hline & Years of schooling & 7.26 & 7.30 & 6.80 \\
\hline & & $(6.27)$ & $(6.27)$ & $(6.23)$ \\
\hline & Returnee & 0.075 & 0.00 & 1.00 \\
\hline & & $(0.26)$ & $(0.00)$ & $(0.00)$ \\
\hline & Real oil price at the age of 20 & 40.19 & 39.41 & 49.84 \\
\hline & & $(20.79)$ & $(20.30)$ & $(24.08)$ \\
\hline & Observations & 5,732 & 5,338 & 394 \\
\hline
\end{tabular}


Table 5: Determinants of total fertility, robustness checks

Dependent variable: total number of children

Husband over 25 OPEC countries GDP growth

\begin{tabular}{|c|c|c|c|c|c|}
\hline & \multicolumn{2}{|c|}{ Husband over 25} & \multicolumn{2}{|c|}{ OPEC countries } & \multirow{2}{*}{$\begin{array}{c}\text { GDP growth } \\
(5)\end{array}$} \\
\hline & $(1)$ & $(2)$ & $(3)$ & (4) & \\
\hline \multirow[t]{2}{*}{ Returnee } & $0.060^{* *}$ & $0.580^{* * *}$ & $0.073^{* * *}$ & $0.469 * *$ & $0.487^{* *}$ \\
\hline & $(0.025)$ & $(0.184)$ & $(0.028)$ & $(0.202)$ & $(0.211)$ \\
\hline \multirow[t]{2}{*}{ Generalized residuals } & & $-0.044^{* * *}$ & & $-0.033^{* *}$ & $-0.036^{* *}$ \\
\hline & & $(0.015)$ & & $(0.016)$ & $(0.017)$ \\
\hline \multirow[t]{2}{*}{ Duration of the wedding } & $0.051^{* * *}$ & $0.049^{* * *}$ & $0.053^{* * *}$ & $0.052^{* * *}$ & $0.053^{* * *}$ \\
\hline & $(0.001)$ & $(0.001)$ & $(0.001)$ & $(0.001)$ & $(0.001)$ \\
\hline \multirow[t]{2}{*}{ Wife, age at the wedding } & $-0.008 * * *$ & $-0.011^{* *}$ & $-0.005^{* *}$ & $-0.007^{* * *}$ & $-0.008 * * *$ \\
\hline & $(0.002)$ & $(0.003)$ & $(0.002)$ & $(0.003)$ & $(0.003)$ \\
\hline \multirow[t]{2}{*}{ Husband, years of schooling } & $-0.004^{* * *}$ & $-0.005^{* * *}$ & $-0.005^{* * *}$ & $-0.005^{* * *}$ & $-0.006^{* * *}$ \\
\hline & $(0.001)$ & $(0.001)$ & $(0.001)$ & $(0.001)$ & $(0.001)$ \\
\hline \multirow[t]{2}{*}{ Mother, primary education } & -0.009 & -0.023 & -0.002 & -0.012 & -0.016 \\
\hline & $(0.019)$ & $(0.020)$ & $(0.020)$ & $(0.020)$ & $(0.021)$ \\
\hline \multirow[t]{2}{*}{ Mother, secondary education } & $-0.137^{* * *}$ & $-0.143^{* * *}$ & $-0.139 * * *$ & $-0.145^{* * *}$ & $-0.150^{* * *}$ \\
\hline & $(0.045)$ & $(0.048)$ & $(0.045)$ & $(0.047)$ & $(0.047)$ \\
\hline \multirow[t]{2}{*}{ Mother, number of children } & $0.013^{* * *}$ & $0.011^{* * *}$ & $0.012^{* * *}$ & $0.010^{* * *}$ & $0.009 * * *$ \\
\hline & $(0.003)$ & $(0.003)$ & $(0.003)$ & $(0.003)$ & $(0.003)$ \\
\hline \multirow[t]{2}{*}{ Distance from health clinic } & $0.001^{*}$ & $0.001^{*}$ & $0.001^{* *}$ & $0.002^{* *}$ & $0.002^{* *}$ \\
\hline & $(0.001)$ & $(0.001)$ & $(0.001)$ & $(0.001)$ & $(0.001)$ \\
\hline \multirow[t]{2}{*}{ Rural areas } & $0.099^{* * *}$ & $0.088 * * *$ & $0.098^{* * *}$ & $0.091^{* * *}$ & $0.082^{* * *}$ \\
\hline & $(0.017)$ & $(0.017)$ & $(0.017)$ & $(0.018)$ & $(0.018)$ \\
\hline \multirow[t]{2}{*}{ Real GDP per capita growth } & & & & & -0.0002 \\
\hline & & & & & $(0.003)$ \\
\hline Regional dummies & Yes & Yes & Yes & Yes & Yes \\
\hline Observations & 5,484 & 5,484 & 5,676 & 5,676 & 5,680 \\
\hline $\operatorname{corr}\left(q_{i}, \hat{q}_{i}\right)$ & 0.551 & 0.553 & 0.555 & 0.556 & 0.566 \\
\hline$\chi^{2}$ & & $27.90^{* * *}$ & & $30.57 * * *$ & $20.56^{* * *}$ \\
\hline
\end{tabular}

Robust standard errors in parentheses; standard errors for specifications (2), (4) and (6) obtained through bootstrapping, 1,000 replications with replacement; $\operatorname{corr}\left(q_{i}, \hat{q}_{i}\right)$ is the correlation between the actual and the predicted number of children; $\chi^{2}$ test on the null hypothesis that the coefficient of the real oil price in the auxiliary regression is equal to zero; ${ }^{* * *} \mathrm{p}<0.01,{ }^{* *} \mathrm{p}<0.05,{ }^{*} \mathrm{p}<0.1$.

Source: Authors' elaboration on ELMPS 2006, www.inflationdata.com and World Bank (2011) 
Table 6: Determinants of total fertility, restrictions on the destination countries

Dependent variable: total number of children

\begin{tabular}{|c|c|c|c|c|c|c|}
\hline & \multicolumn{2}{|c|}{ Gulf countries } & \multirow{2}{*}{$\begin{array}{c}1980 \\
(3)\end{array}$} & \multirow{2}{*}{$\begin{array}{c}1985 \\
(4)\end{array}$} & \multirow{2}{*}{$\begin{array}{c}1990 \\
(5)\end{array}$} & \multirow{2}{*}{$\begin{array}{c}1995 \\
(6)\end{array}$} \\
\hline & (1) & $(2)$ & & & & \\
\hline \multirow[t]{2}{*}{ Returnee } & $0.072^{* *}$ & $0.440^{* *}$ & $0.535^{* * *}$ & $0.568^{* * *}$ & $0.557^{* * *}$ & $0.432^{* *}$ \\
\hline & $(0.029)$ & $(0.191)$ & $(0.190)$ & $(0.178)$ & $(0.179)$ & $(0.176)$ \\
\hline \multirow[t]{2}{*}{ Generalized residuals } & & $-0.031^{* *}$ & $-0.039 * *$ & $-0.041 * * *$ & $-0.040 * * *$ & $-0.031^{* *}$ \\
\hline & & $(0.015)$ & $(0.016)$ & $(0.014)$ & $(0.014)$ & $(0.014)$ \\
\hline \multirow[t]{2}{*}{ Duration of the wedding } & $0.054^{* * *}$ & $0.052^{* * *}$ & $0.052^{* * *}$ & $0.052^{* * *}$ & $0.052^{* * *}$ & $0.052^{* * *}$ \\
\hline & $(0.001)$ & $(0.001)$ & $(0.001)$ & $(0.001)$ & $(0.001)$ & $(0.001)$ \\
\hline \multirow[t]{2}{*}{ Wife, age at the wedding } & $-0.005^{*}$ & $-0.007 * *$ & $-0.008^{* * *}$ & $-0.008^{* * *}$ & $-0.008^{* * *}$ & $-0.007^{* *}$ \\
\hline & $(0.002)$ & $(0.003)$ & $(0.003)$ & $(0.003)$ & $(0.003)$ & $(0.003)$ \\
\hline \multirow[t]{2}{*}{ Husband, years of schooling } & $-0.005^{* * *}$ & $-0.005^{* * *}$ & $-0.005^{* * *}$ & $-0.005^{* * *}$ & $-0.005^{* * *}$ & $-0.005^{* * *}$ \\
\hline & $(0.001)$ & $(0.001)$ & $(0.001)$ & $(0.001)$ & $(0.001)$ & $(0.001)$ \\
\hline \multirow[t]{2}{*}{ Mother, primary education } & 0.000 & -0.009 & -0.014 & -0.010 & -0.009 & -0.007 \\
\hline & $(0.020)$ & $(0.021)$ & $(0.021)$ & $(0.021)$ & $(0.021)$ & $(0.021)$ \\
\hline \multirow[t]{2}{*}{ Mother, secondary education } & $-0.139 * * *$ & $-0.146^{* * *}$ & $-0.143^{* * *}$ & $-0.144^{* * *}$ & $-0.145^{* * *}$ & $-0.148^{* * *}$ \\
\hline & $(0.045)$ & $(0.047)$ & $(0.048)$ & $(0.049)$ & $(0.049)$ & $(0.049)$ \\
\hline \multirow[t]{2}{*}{ Mother, number of children } & $0.012^{* * *}$ & $0.010^{* * *}$ & $0.011^{* * *}$ & $0.011^{* * *}$ & $0.011^{* * *}$ & $0.011^{* * *}$ \\
\hline & $(0.003)$ & $(0.003)$ & $(0.003)$ & $(0.003)$ & $(0.003)$ & $(0.003)$ \\
\hline \multirow[t]{2}{*}{ Distance from health clinic } & $0.001^{* *}$ & $0.002^{* *}$ & $0.002^{* *}$ & $0.001^{* *}$ & $0.001^{*}$ & $0.001^{*}$ \\
\hline & $(0.001)$ & $(0.001)$ & $(0.001)$ & $(0.001)$ & $(0.001)$ & $(0.001)$ \\
\hline \multirow[t]{2}{*}{ Rural areas } & $0.097^{* * *}$ & $0.095^{* * *}$ & $0.088 * * *$ & $0.087^{* * *}$ & $0.088 * * *$ & $0.093^{* * *}$ \\
\hline & $(0.017)$ & $(0.017)$ & $(0.018)$ & $(0.018)$ & $(0.018)$ & $(0.017)$ \\
\hline Regional dummies & Yes & Yes & Yes & Yes & Yes & Yes \\
\hline Observations & 5,644 & 5,644 & 5,727 & 5,705 & 5,703 & 5,658 \\
\hline $\operatorname{corr}\left(q_{i}, \hat{q}_{i}\right)$ & 0.556 & 0.557 & 0.558 & 0.558 & 0.558 & 0.557 \\
\hline$\chi^{2}$ & & $40.09 * * *$ & $26.20^{* * *}$ & $32.95^{* * *}$ & $33.51^{* * *}$ & $37.63^{* * *}$ \\
\hline
\end{tabular}

Robust standard errors in parentheses; standard errors for specifications (2)-(6) obtained through bootstrapping, 1,000 replications with replacement; $\operatorname{corr}\left(q_{i}, \hat{q}_{i}\right)$ is the correlation between the actual and the predicted number of children; $\chi^{2}$ test on the null hypothesis that the coefficient of the real oil price in the auxiliary regression is equal to zero; (3) excludes returnees from Lebanon; (4) excludes returnees from Kuwait, Lebanon and Qatar; (5) excludes returnees from Algeria, Kuwait, Lebanon and Qatar; (6) excludes returnees from Algeria Kuwait, Lebanon, Libya and Qatar; ${ }^{* * *} \mathrm{p}<0.01,{ }^{* *}$ $\mathrm{p}<0.05,{ }^{*} \mathrm{p}<0.1$.

Source: Authors' elaboration on ELMPS 2006 and www.inflationdata.com 
Figure 1: Share of returnees by year of birth and real oil price at the age of 20

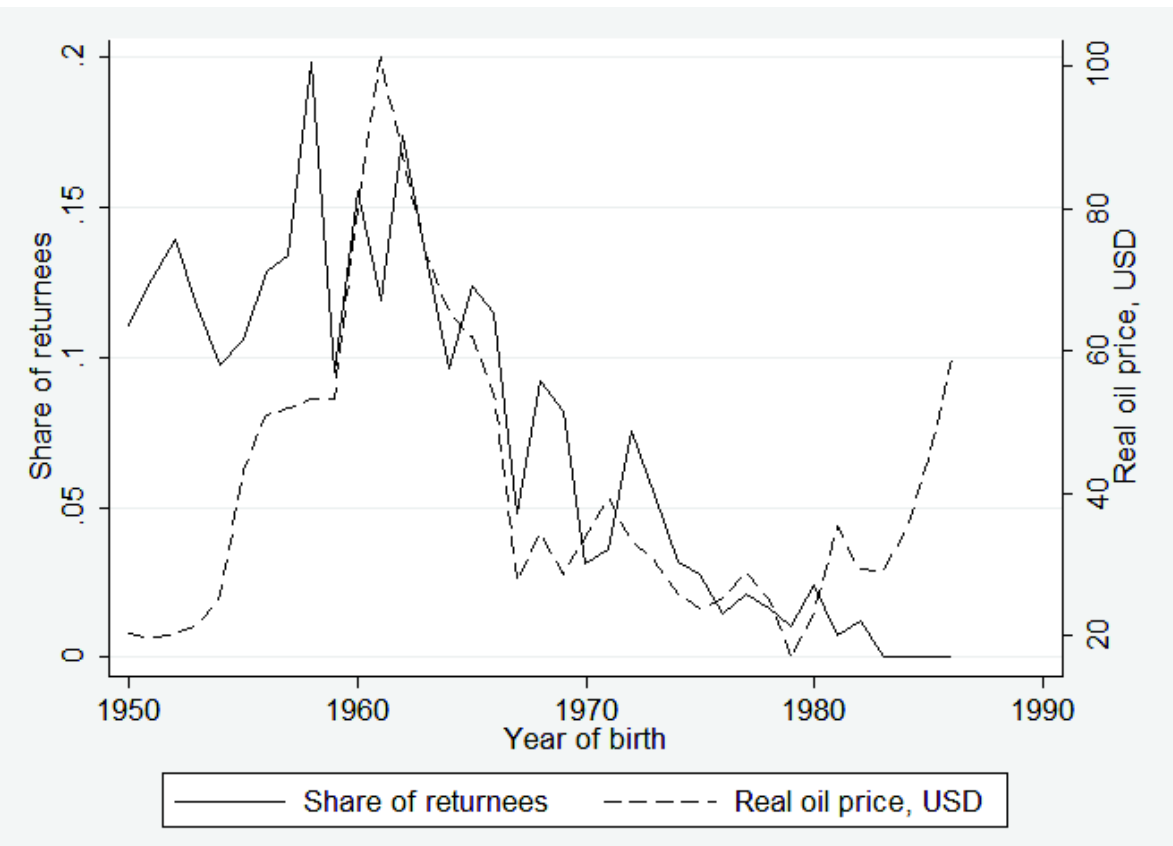

Source: Authors' elaboration on ELMPS 2006 and www.inflationdata.com 
Figure 2: Share of returnees by year of birth and real oil price at the age of 20

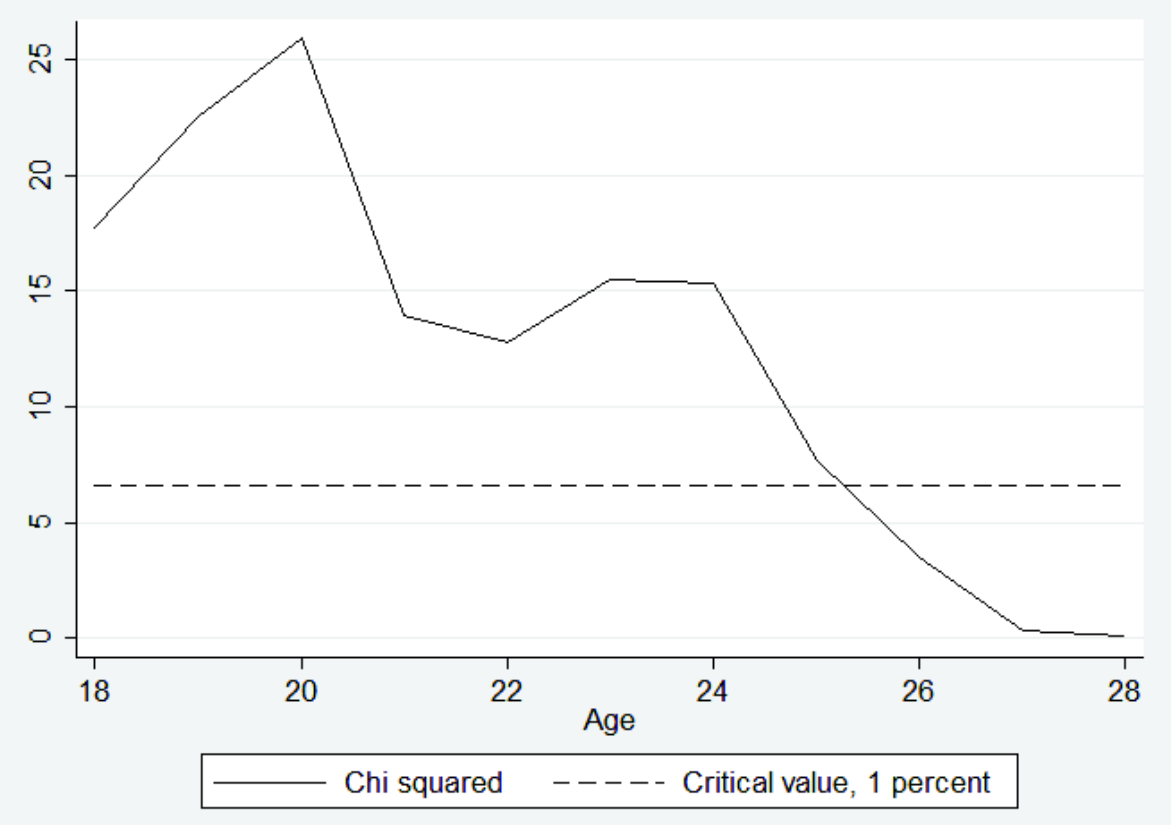

Source: Authors' elaboration on ELMPS 2006 and www.inflationdata.com 